\title{
ANN Approach to Predict the Flow Stress of CMn (Nb-Ti-V) Micro Alloyed Steel
}

\author{
Allaoui Abdelhalim \\ Department of Metallurgy and Materials Engineering, Badji Mokbtar University, Annaba, Algeria \\ balim_allaoui23@yahoo.fr, bttp:/ /orcid.org/0000-0001-2345-6789
}

Guedri Abdelmoumene, Darsouni Lamia

Infra-Res Laboratory, University of Souk. Abras, Souk. Ahras, Algeria

Foundry Laboratory, Badji Mokbtar University, Annaba, Algeria

guedri_moumen@yahoo.fr,bttp://orcid.org/0000-0002-2345-6790

ch-lamia@botmail.fr, bttp://orcid.org/0000-0002-2345-6791

\section{Darsouni Abderrazek}

Foundry Laboratory, Badji Mokbtar University, Annaba, Algeria

darsouniabdel@yahoo.fr,.bttp://orcid.org/0000-0003-2345-6792

\begin{abstract}
The flow behavior of CMn (Nb-Ti-V) micro alloyed steel was studied by hot compression tests in a wide range of temperatures $\left(700{ }^{\circ} \mathrm{C}\right.$ to $1050{ }^{\circ} \mathrm{C}$, Step $\left.50{ }^{\circ} \mathrm{C}\right)$, strain rates $\left(0.000734 \mathrm{~s}^{-1}, 0.0029 \mathrm{~s}^{-1}\right.$, and $\left.0.0146 \mathrm{~s}^{-1}\right)$ and true strain of 0 to 0.8 . Based on the experimental true stress-plastic strain data, the artificial neural network (ANN) methods were employed to predict the flow stress of $\mathrm{CMn}(\mathrm{Nb}-\mathrm{Ti}-\mathrm{V})$. The ANN model was trained with LevenbergMarquardt (LM) algorithm. The optimal LM neural network model with two hidden layer network with ten neurons in the first and ten neurons in the second gives the best predictions is developed. It is demonstrated that the LV neural network model has better performance in predicting the flow stress. The results can be further used in mathematical simulation of hot metal forming processes.
\end{abstract}

KEYwORDS. Flow Stress; Micro Alloyed Steel; Artificial Neural Network; Hot Compression Tests.

\section{OPEN ACCESS}

Citation: Allaoui, A., Guedri, A., Darsouni, L., Darsouni, A., ANN Approach to Predict the Flow Stress of CMn (Nb-Ti-V) Micro Alloyed Steel Based on Compression Tests, Frattura ed Integrità Strutturale, 49 (2019) 350-359.

Received: 13.03 .2019

Accepted: 10.05 .2019

Published: 01.07.2019

Copyright: (C) 2019 This is an open access article under the terms of the CC-BY 4.0, which permits unrestricted use, distribution, and reproduction in any medium, provided the original author and source are credited.

\section{INTRODUCTION} o optimize the technology of a metal forming operation, it is necessary to experiment the constituent relationships relating process variables such as temperature, strain rate and deformation to the flow stress of the deforming material [1]. Appropriate modeling of hot deformation curves is the first step in a mathematical simulation of hot 
deformation processes, such as hot forging and hot rolling. A more widely adopted approach is to obtain constitutive equations from experimentally determined flow curves [2]. Therefore, many researchers have opted for empirical methods through which they relate the process variables to the flow stress [3-5]. Recent studies [6-8] have shown that the methodology of neural networks can be adopted to resolve problems, which are difficult to answer using traditional methods, and demonstrated that ANN techniques can model hot deformation flow curves of different materials. The objective of this study is to predict the flow stress of micro-alloy steel CMn (Nb-Ti-V) using a neural network approach.

\section{EXPERIMENTS}

\section{Material and Experiment Procedures}

he hot compression test is the most suitable of all the deformation tests for the study of the rheological parameters, because it makes it possible to obtain a homogeneous deformation in the sample from an improvement of the lubrication conditions to the sample-heap interface of the machine. The compression test also makes it possible to achieve deformations of the order of unity. The hot compression device is shown in Fig.1. It also allows the quenching of the sample at the end of the test. The heating is done by radiation in a quartz tube, which ensures the best compromise between the flexibility of use and the rate of rise in temperature using six infrared lamps placed at the focus of a dish. The heating zone is larger with a homogeneous temperature.

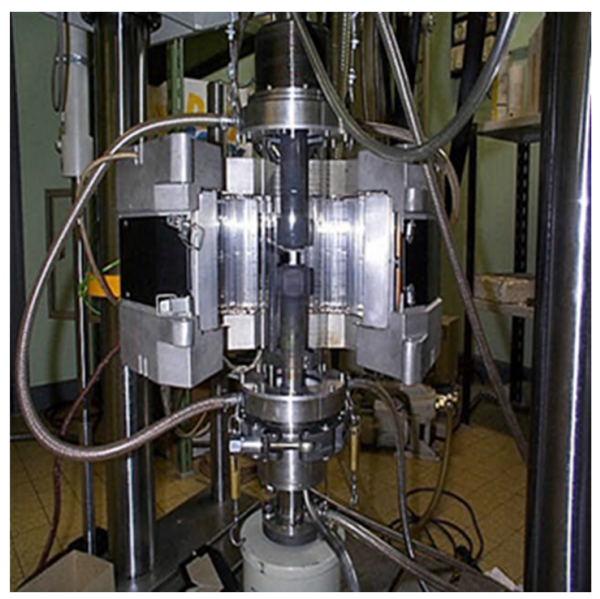

Figure 1: Experimental equipment of the compression tests

The compression test also makes it possible to achieve deformations of the order of unity. The hot compression device is shown in Fig.1. It also allows the quenching of the sample at the end of the test. The heating is done by radiation in a quartz tube, which ensures the best compromise between the flexibility of use and the rate of rise in temperature using six infrared lamps placed at the focus of a dish. The heating zone is larger with a homogeneous temperature.

The compression test is controlled by a computer and provides the position regulation of the cross during the rise in temperature, so that the upper pile always remains in contact with the sample. A programmer managed by microprocessor allows performing complex thermomechanical cycles. The maximum permissible temperatures in this model are of the order of $1300{ }^{\circ} \mathrm{C}$. The force is measured continuously. When this exceeds a certain threshold, the cross is automatically raised to cancel the force. In this way, the effect of dilation is compensated. The samples used are cylindrical with a diameter of $7.8 \mathrm{~mm}$ and a height of $11.3 \mathrm{~mm}$. Before deformation, our samples are heated inside the compression device up to the test temperature at a rate of $100{ }^{\circ} \mathrm{C}$ per minute.

The temperature is controlled by two thermocouples placed one above and one below the sample. As soon as the test is finished, the upper pile of the machine rises automatically to allow us to soak our samples very quickly using a finger that is actuated from the outside. The compression tests were carried out at temperatures between $700{ }^{\circ} \mathrm{C}$ and $1050{ }^{\circ} \mathrm{C}$, for deformation rates going from $\left(0.000734,0.0029\right.$, and $\left.0.0146 \mathrm{~s}^{-1}\right)$, depending on the cycle shown in Fig. 2. This cycle aims is a gradual precipitation of the additive elements. After homogenization of the structure by heating at $1300{ }^{\circ} \mathrm{C}$ followed by quenching with water, the specimens are fixed in the compression device where they undergo a solution treatment at 
$1050{ }^{\circ} \mathrm{C}$. Then they are cooled to the deformation temperature, which is between $700{ }^{\circ} \mathrm{C}$ and $1050{ }^{\circ} \mathrm{C}$. Tab. 1 Show detailed chemical compositions and Figs. (3-4) present starting microstructure. The average grain size is about $40 \mu \mathrm{m}$.

\begin{tabular}{cccccccccc}
\hline$\% \mathrm{C}$ & $\% \mathrm{~S}$ & $\% \mathrm{P}$ & $\% \mathrm{Al}$ & $\% \mathrm{Si}$ & $\% \mathrm{Mn}$ & $\% \mathrm{~V}$ & $\% \mathrm{Nb}$ & $\% \mathrm{Ti}$ \\
0.044 & 0.012 & 0.012 & 0.017 & 0.22 & 1.45 & 0.053 & 0.080 & 0.041 \\
\hline
\end{tabular}

Table 1: The detailed chemical compositions

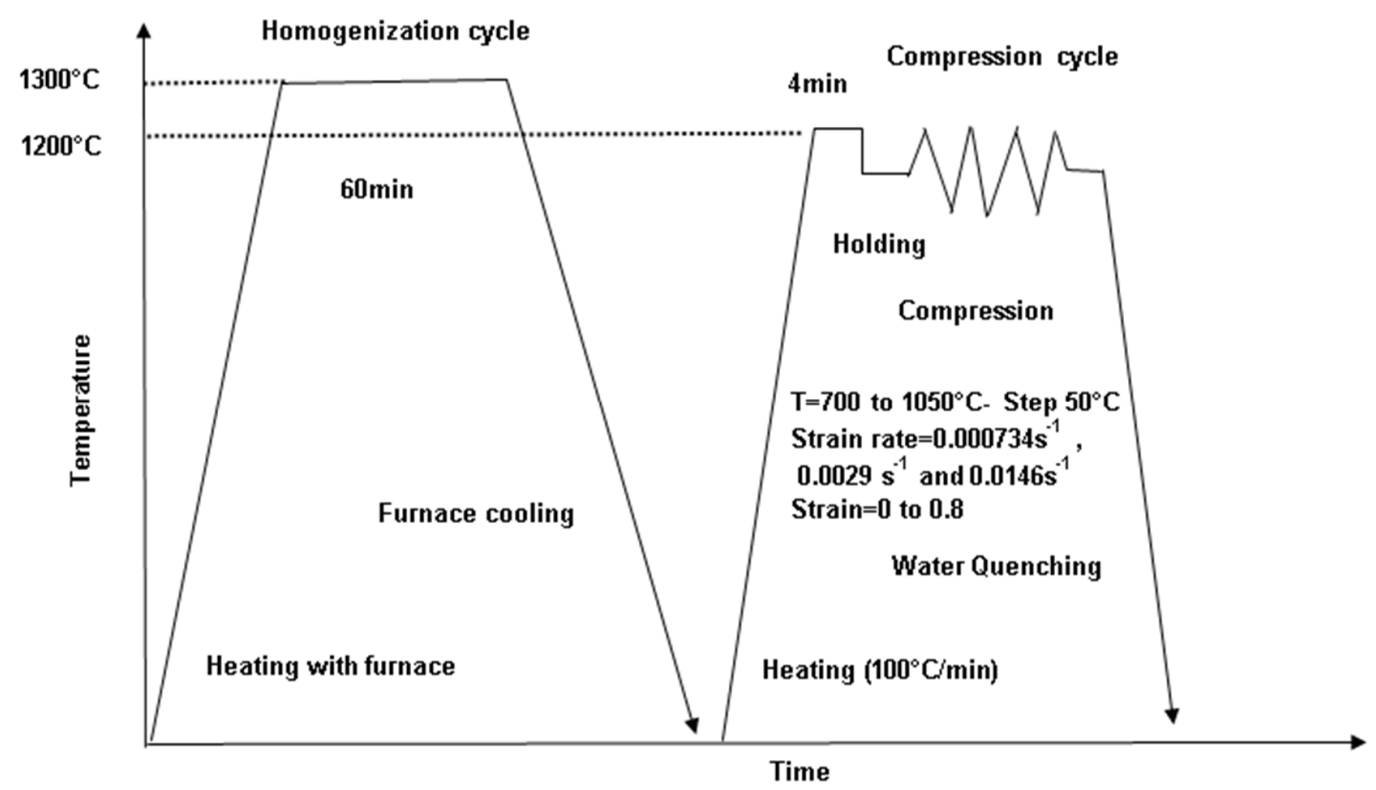

Figure 2: Experimental procedures for the compression tests of $\mathrm{CMn}(\mathrm{Nb}-\mathrm{Ti}-\mathrm{V})$ micro alloyed steel.

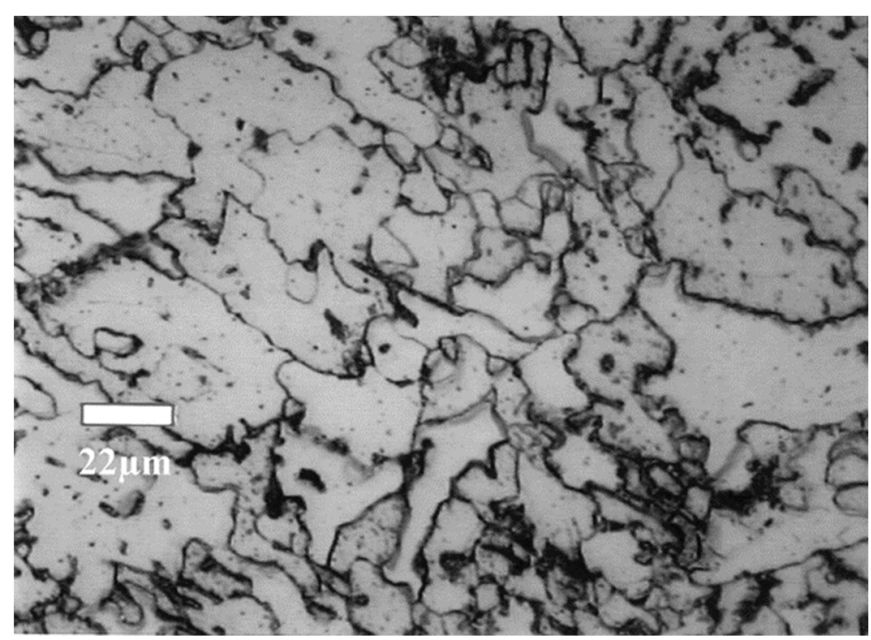

Figure 3: Microstructure of the raw steel casting

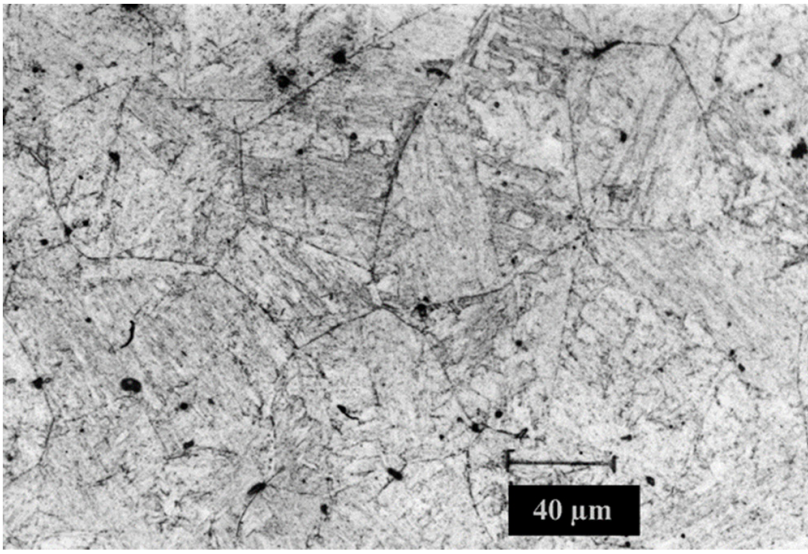

Figure 4: Raw casting sample quenched after austenization at $1300{ }^{\circ} \mathrm{C}$.

\section{Experimental Results}

Figs. (5-7) show real stress-strain curves resulted from hot compression at different temperatures (from $700{ }^{\circ} \mathrm{C}$ to $1050{ }^{\circ} \mathrm{C}$ ) and strain rates values of $0.0146 \mathrm{~s}^{-1}, 0.0029 \mathrm{~s}^{-1}$ and $0.000734 \mathrm{~s}^{-1}$. their paces suggest classifying them in three types a, b and $\mathrm{c}$, according to the different ranges of temperature:

○ The stress increases rapidly and decreases with a significant slope $\left(700{ }^{\circ} \mathrm{C}\right.$ and $\left.750{ }^{\circ} \mathrm{C}\right)$ (type a);

- The stress increases rapidly until reaching a plateau $\left(800^{\circ} \mathrm{C}\right.$ and $\left.850^{\circ} \mathrm{C}\right)$ (type b); 
- The stress raises up to a maximum after which it decreases more or less rapidly to reach a stationary state (austenitic domain) (type c).

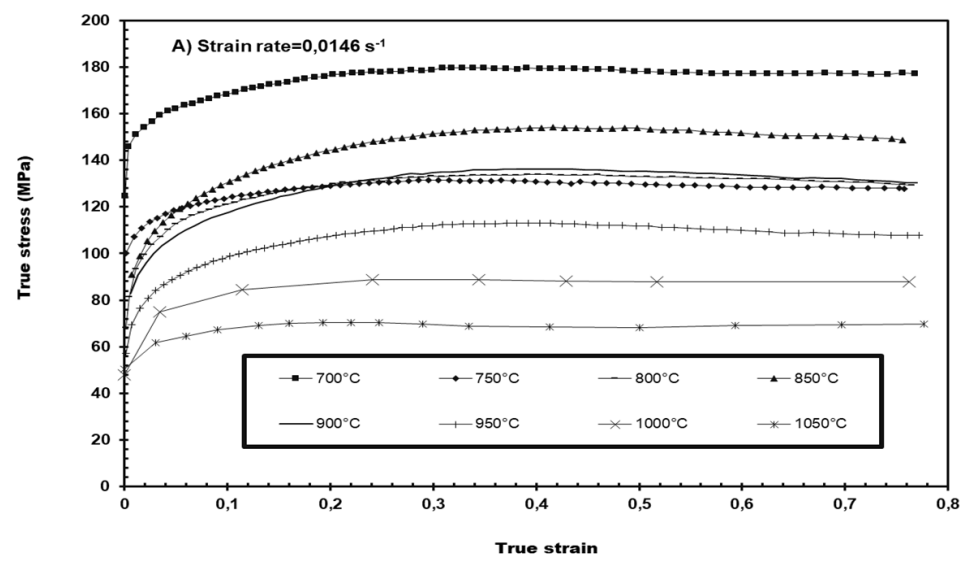

Figure 5: Stress-strain curves under different temperatures with a value of $0.0029 \mathrm{~s}^{-1}$ strain rate.

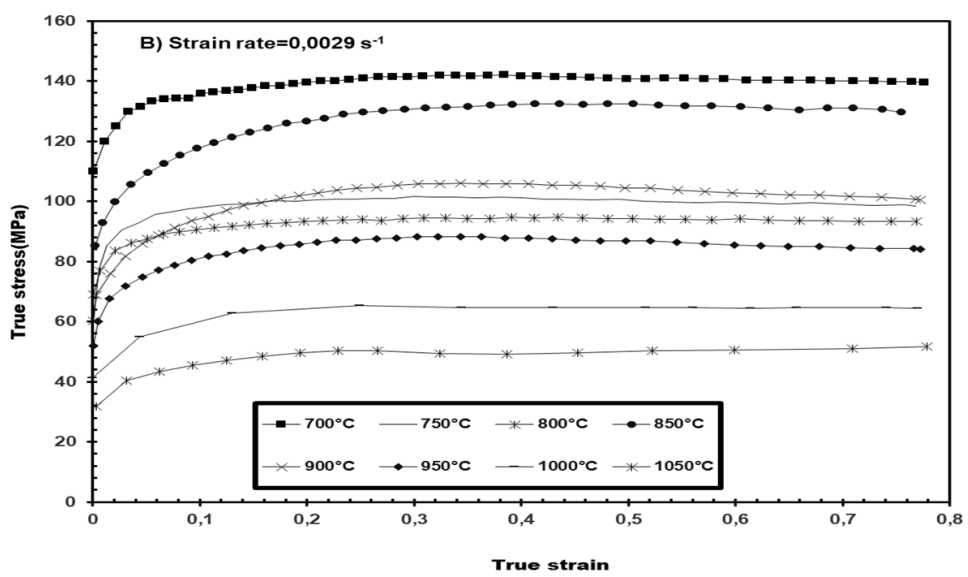

Figure 6: Stress-strain curves under different temperatures with a value of $0.0146 \mathrm{~s}^{-1}$ strain rate-

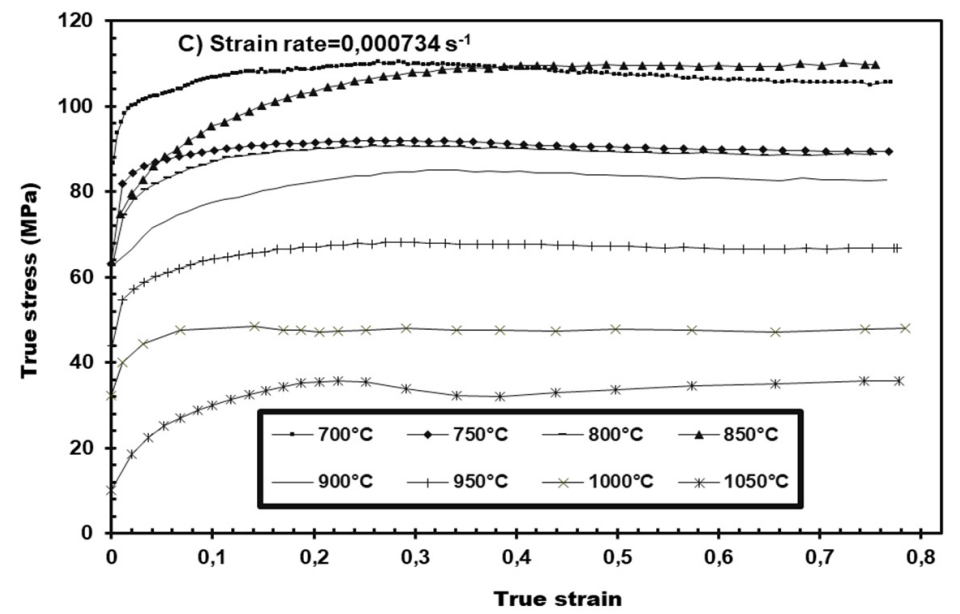

Figure 7: Stress-strain curves under different temperatures with a value of $0.000734 \mathrm{~s}^{-1}$ strain rate - 
ANN MODEL

\section{Development of ANN Model}

T $\mathrm{n}$ this work, an ANN model for the compression flow behaviors of CMn ( Nb-Ti-V) micro-alloyed steel was developed. The input variables are temperature $(\mathrm{T})$, strain rate $(\dot{\varepsilon})$ and strain $(\varepsilon)$, and the output variable is the flow stress $\left(\sigma_{\mathrm{f}}\right)$. The material flow stress $\left(\sigma_{f}\right)$ depends on the independent variables $(\varepsilon, \dot{\varepsilon}, T)$ during hot working process. Therefore, the input layer is composed of three neurons representing these variables. The flow stress is represented by the neuron in the output layer. MATLAB was used to train the neural network. It used the Levenberg-Marquardt algorithm, which is known to be highly efficient in solving problems of non-linear optimization. The total data of the ANN model, which consists of 1168 input—output data sets, are derived from the 24 stress-strain curves. These data were subdivided into three groups. The first group consists of 590 data sets and is used to train the network. The second group is composed of 287 and is used to evaluate the generalisation. Finally the last group, which consists of 291 data sets, is used to validate the ANN model.

In looking for the best ANN model, one has to determine the appropriate number of hidden layers and the number of neurons in each one. This is done though training and testing of different network structures and the appropriate one should ultimately be determined by evaluating tolerance between predicted and experimental data. Mean square error, MSE, indicator as shown in Eqn. (1) was introduced to evaluate the training and generalization performances of ANN [7].

$$
M S E=\frac{1}{N} \sum_{i=1}^{N}(E i-P i)^{2}
$$

where $\mathrm{E}$ and $\mathrm{P}$ are experimental and predicted flow stress values respectively and $\mathrm{N}$ the number of data sets.

The training and testing exercise as indicated in the previous paragraph resulted in a network of two hidden layers with ten neurons in each one. This network produced an MSE value of 0.15 as shown in Fig. 8. The resulted network is shown in Fig. 9.

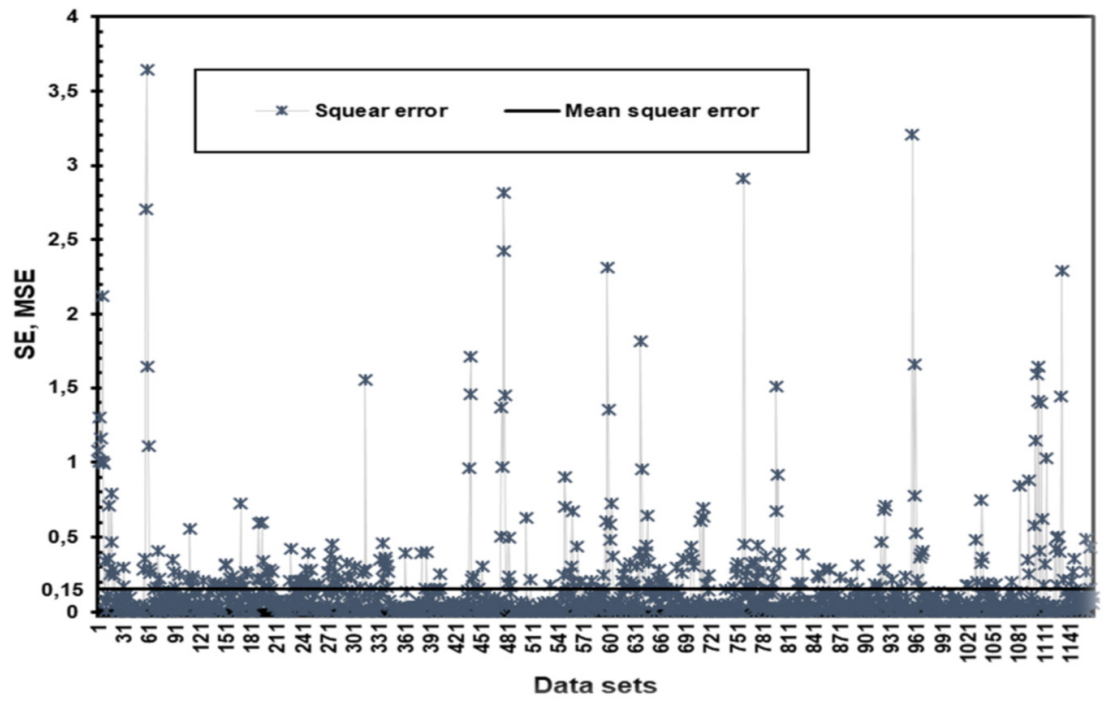

Figure 8: The square error (SE) of all data and the mean square error (MSE)

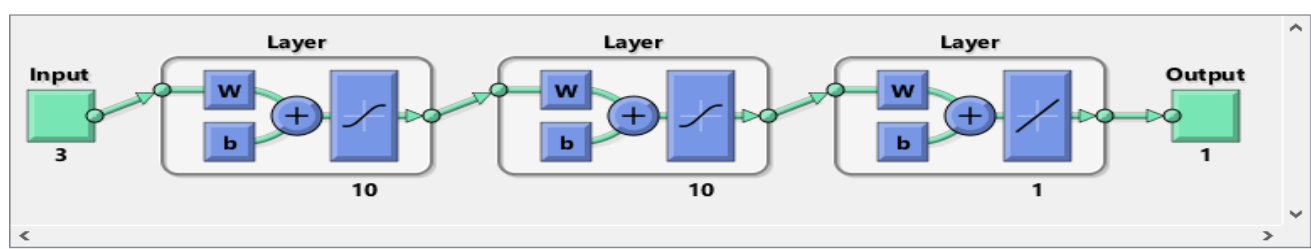

Figure 9: The architecture of the optimal artificial neural network (ANN) model 
Results of the developed neural network

The predictability of ANN model is verified in this study using two statistical indicators: the absolute relative error (AARE) and the correlation coefficient (R) [8]. These indicators are given in Eqns. (2) and (3). The higher value of R close to one illustrates that the predicted values conform to the experimental ones well; meanwhile, a low AARE-value close to zero indicates that the sum of the errors between the predicted and experimental values tend to be zero. Thereby, such $\mathrm{R}$ and AARE are expected.

$$
\begin{aligned}
& \mathrm{R}=\frac{\sum_{i=1}^{N}\left(E_{i}-\bar{E}\right)\left(P_{i}-\bar{P}\right)}{\sqrt{\sum_{i=1}^{N}\left(E_{i}-\bar{E}\right)^{2} \sum_{i=1}^{N}\left(P_{i}-\bar{P}\right)^{2}}} \\
& A A R E(\%)=\frac{100}{N} \sum_{i=1}^{N}\left|\frac{P_{i}-E_{i}}{E_{i}}\right|
\end{aligned}
$$

In which $\mathrm{E}$ and $\mathrm{P}$ are respectively the experimental value and predicted value of true stress; $\overline{\mathrm{E}}$ and $\overline{\mathrm{P}}$ are the mean values of $\mathrm{E}$ and $\mathrm{P}$ respectively; $\mathrm{N}$ the number of data sets.

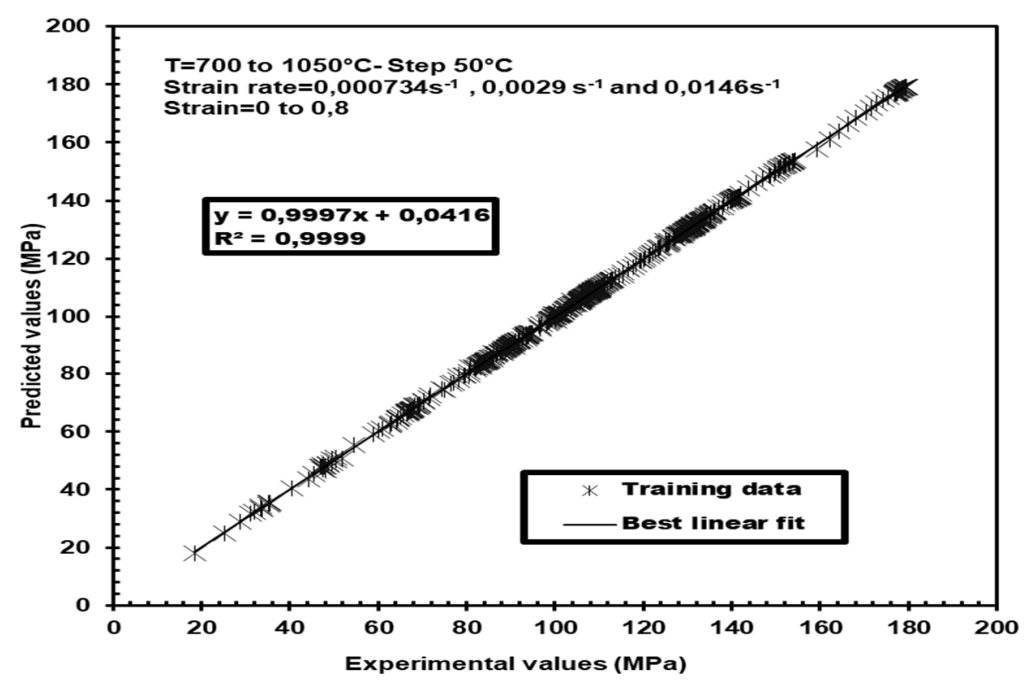

Figure 10-a: Experimental versus predicted flow stress for the training set

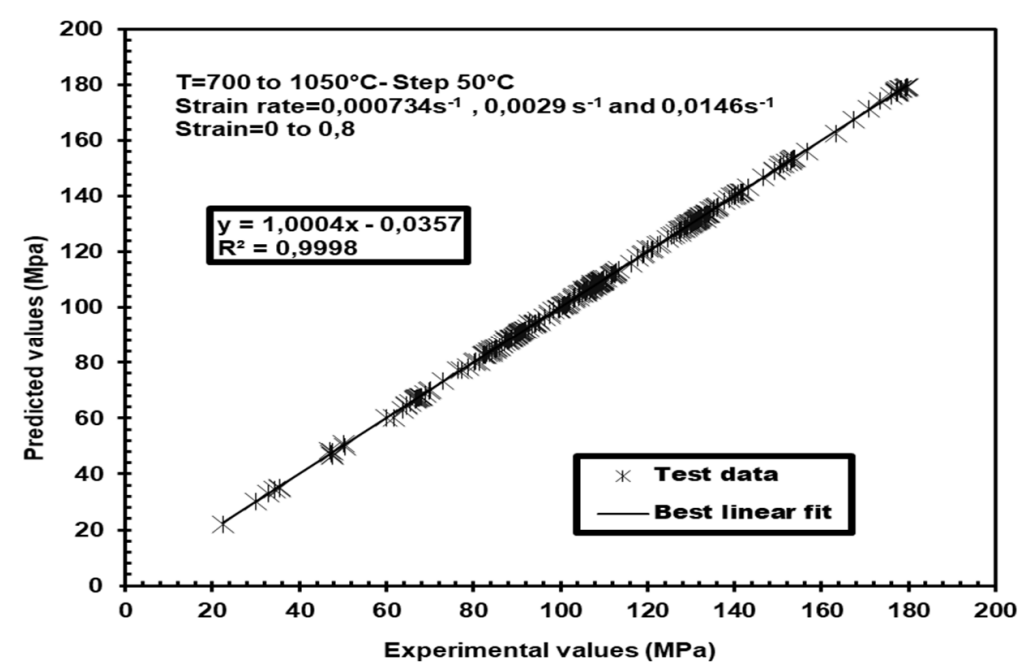

Figure 10-b: Experimental versus predicted test flow stress data set 


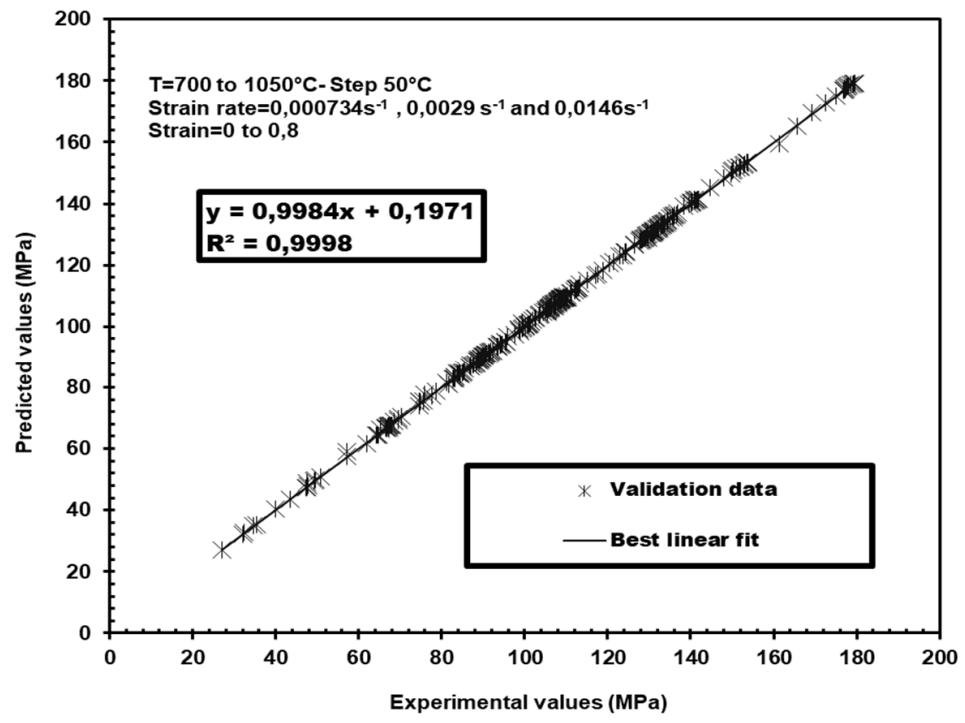

Figure 10-c: Experimental versus predicted validation flow stress data set.

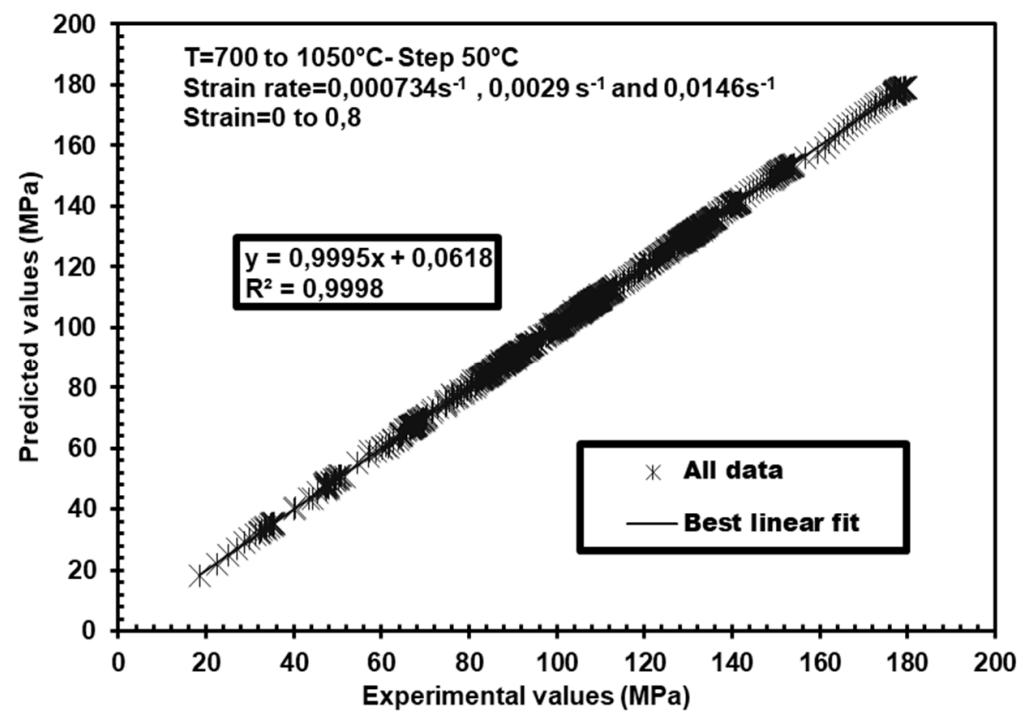

Figure 10-d: Experimental versus predicted all flow stress data set.

The ANN model resulted from the previous sections is used hereafter to predict the deformation conditions, which corresponds to test points and previous training points. Figs. (10-a, b, c, and d) show predicted and experimental flow stress values along with their correlation relationships. The best-fit line corresponds to the 45 degrees line. The figures show that all errors between predicted and observed flow stress values are lower the $5 \%$. Likewise, the resulting correlation coefficients between observed and predicted values are 0.9999 and 0.9998 for the training and testing data sets, respectively.

As indicated in the above, high correlation coefficient would indicate a good prediction capacity of the model. Similarly, AAR is used as an alternative goodness fit test as shown in Fig. 11 . The AAR value was found to be equal to $0.31 \%$ for all data sets. This low error would indicate the high accuracy of the ANN model for both testing and training data sets.

Figs. 12 and 13 show the results of training, test and validation for stress strain curves with a maximum relative error of $3.1 \%$ for the experimental conditions shown in the corresponding figures. These results would confirm, and therefore, validate the learning and generalisation capacity of the ANN model.

A comparison between initial experimental curves and ANN predicted stress-strain values are presented in Figs. (14, 15, and 16). The predicted data show that the ANN model is able to precisely reproduce the evolution rules that govern the stress-strain relationships. Hence, when the temperature increases, the stress and its rate decrease. Therefore, the obtained 
ANN model was capable to follow the dynamic softening regions and hardening work of $\mathrm{CMn}(\mathrm{Nb}-\mathrm{Ti}-\mathrm{V})$ micro-alloyed steel.

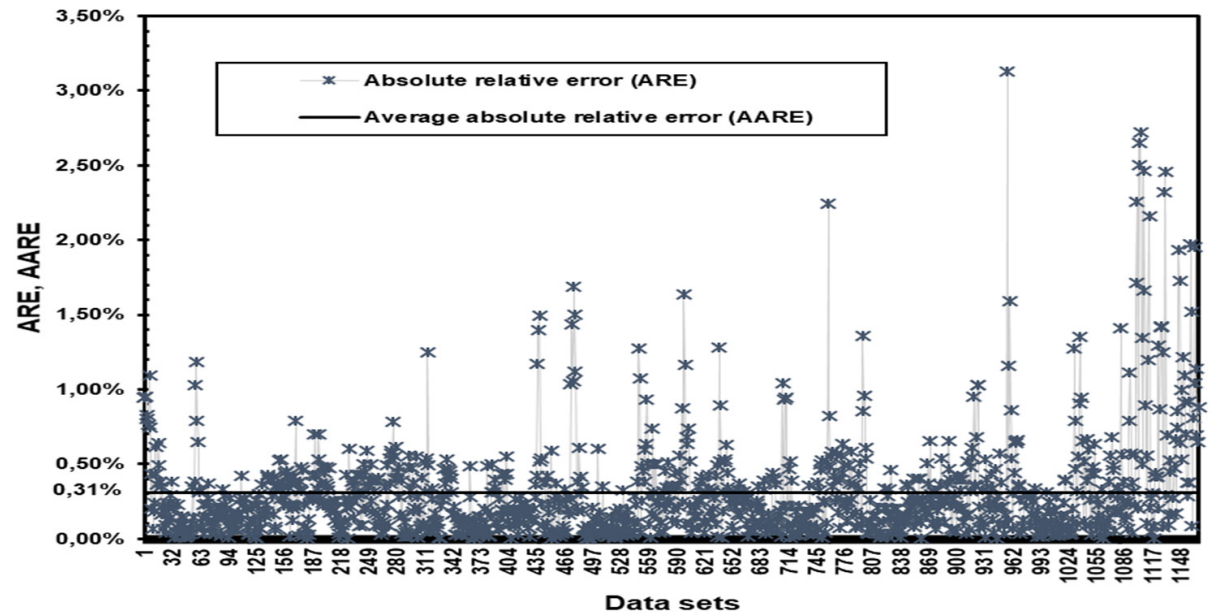

Figure 11: The absolute relative error (ARE) of all data and the average absolute relative error (AARE)

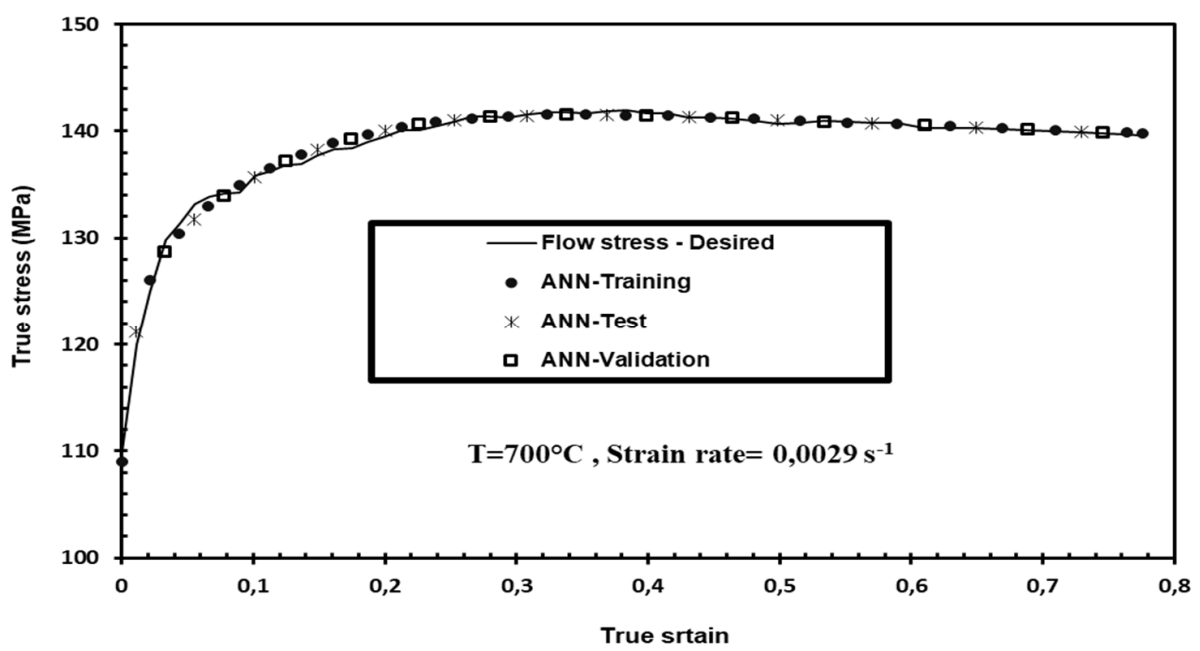

Figure 12: Experimental versus predicted flow stress values for Strain rate $=0.0029 \mathrm{~S}^{-1}$ and at $\mathrm{T}=700^{\circ} \mathrm{C}$

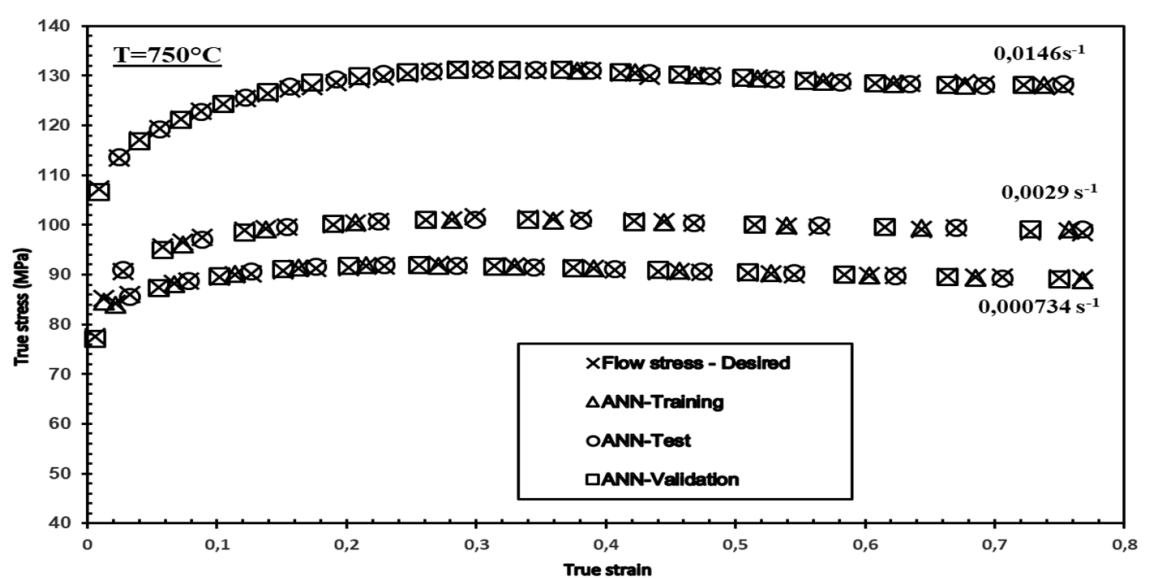

Figure 13: Experimental versus predicted flow stress values for different strain rates values at $\mathrm{T}=750^{\circ} \mathrm{C}$ 


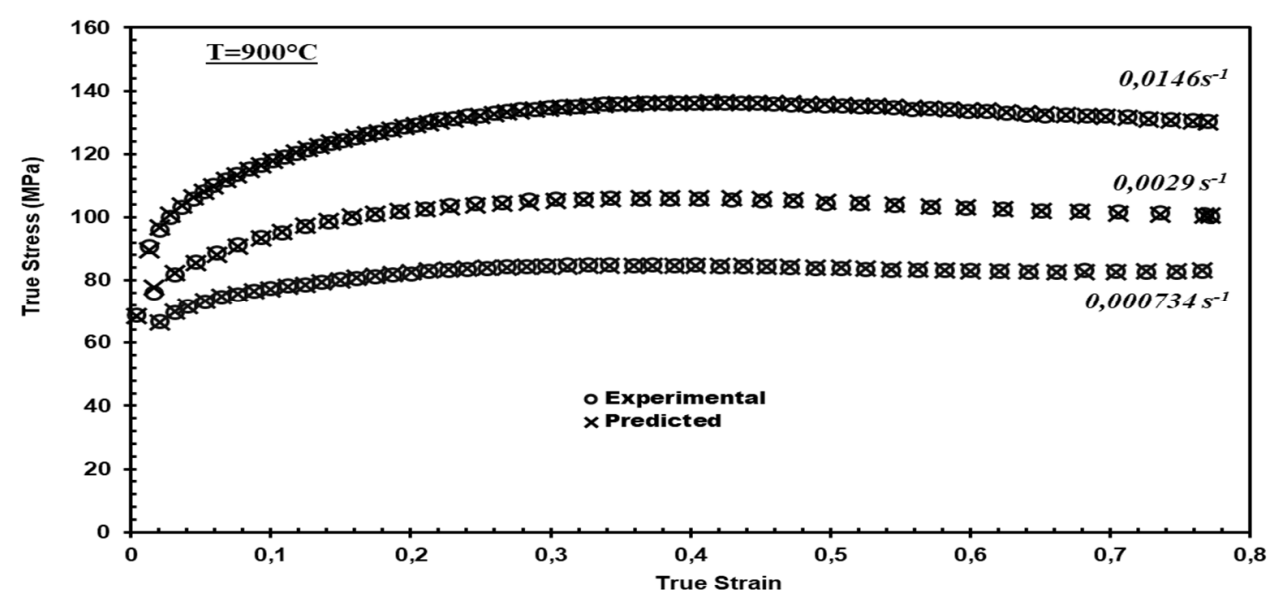

Figure 14: Experimental versus predicted flow stress values for different strain rates at $\mathrm{T}=900{ }^{\circ} \mathrm{C}$

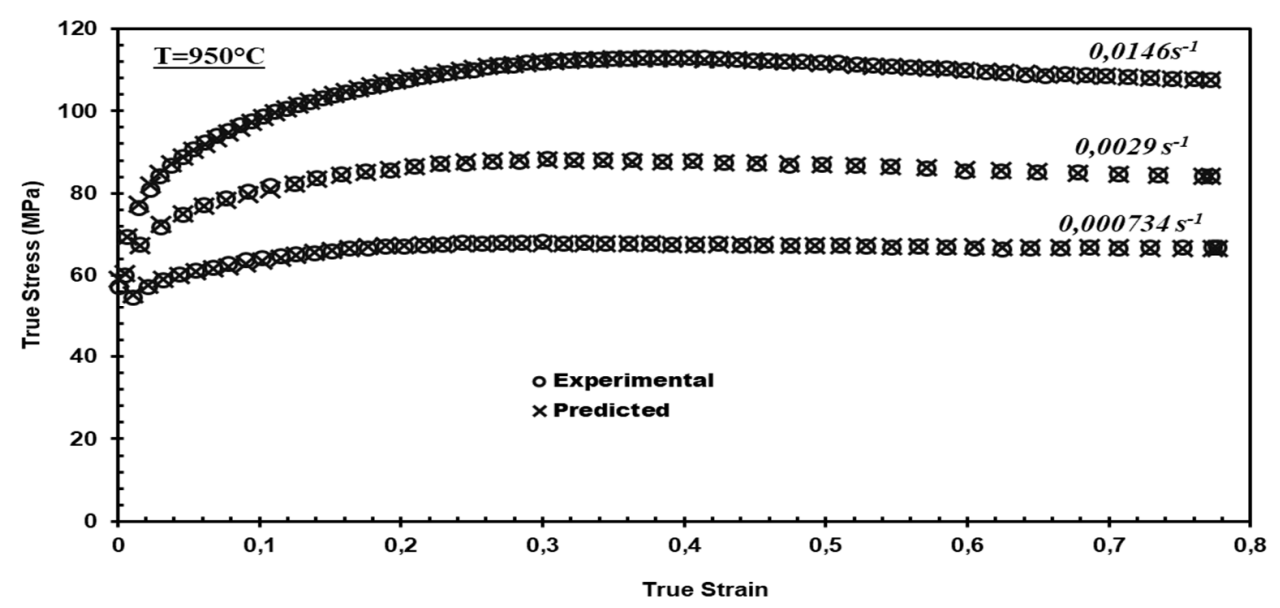

Figure 15: Experimental versus predicted flow stress values for different strain rates at $\mathrm{T}=950{ }^{\circ} \mathrm{C}$

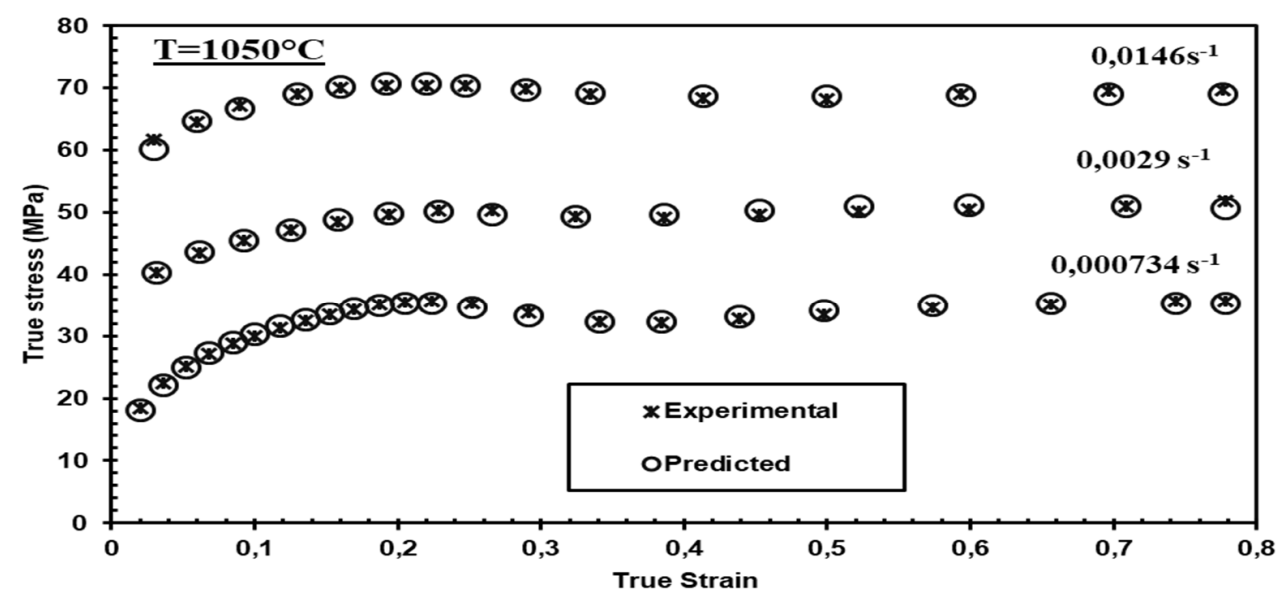

Figure 16: Experimental versus predicted flow stress values for different strain rates at $\mathrm{T}=1050{ }^{\circ} \mathrm{C}$

Fig.17 shows the evolution of the maximum stress as a function of the strain rate and the temperature. These curves are characterized by a decrease in the stress between $700{ }^{\circ} \mathrm{C}$ and $750{ }^{\circ} \mathrm{C}$, followed by an increase between $750{ }^{\circ} \mathrm{C}$ and $850{ }^{\circ} \mathrm{C}$. Finally, beyond $850^{\circ} \mathrm{C}$, the maximum stress decreases rapidly. Indeed, the maximum stress decreases at the beginning of the two-phase domain, then increases with the increase of the volume fraction of the austenitic phase to reach a maximum 
at the AC3 point. Dilatometry measurements were made on our material to determine allotropic transformation points $\mathrm{AC} 1=710^{\circ} \mathrm{C}$ and $\mathrm{AC} 3=850^{\circ} \mathrm{C}$.

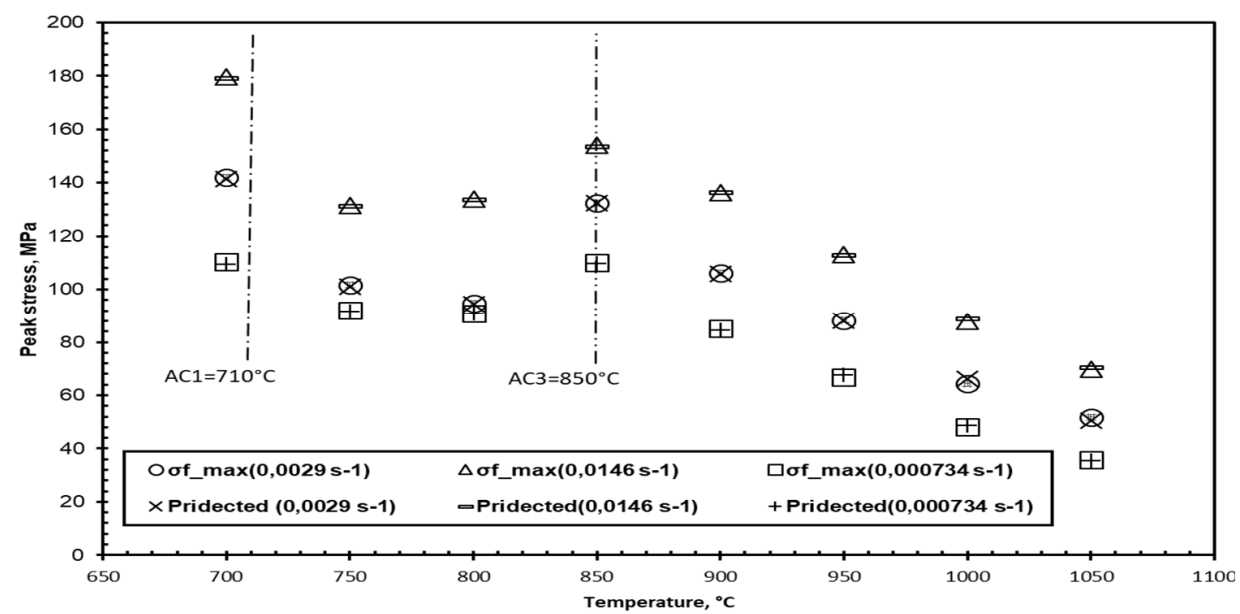

Figure 17: Experimental versus predicted peak stresses values for different temperatures and strain rates values

\section{CONCLUSIONS}

A model based on artificial neural networks has been developed in order to predict the response of the deformation of micro alloyed steel subjected to hot compression. The experimental data ranges from $700{ }^{\circ} \mathrm{C}$ to $1050{ }^{\circ} \mathrm{C}$ in temperature for strain rate values of $0.000734 \mathrm{~s}^{-1}, 0.0029 \mathrm{~s}^{-1}$ and $0.0146 \mathrm{~s}^{-1}$. The output variable of the ANN model is the compressional flow stress and the input variables are temperature, strain rate and strain. The LevenbergMarquardt algorithm was used to train the model.

The resulting network architecture is composed of three neurons in input layer followed by two hidden layers composed of ten neurons each and ends with a one-neuron output layer. The ANN model predicts well the flow stress behaviour and precisely follow dynamic softening, flow localization regions and work hardening of the deforming material. We can conclude with confidence that the proposed model can reliably predict the deformation response of $\mathrm{CMn}(\mathrm{Nb}-\mathrm{Ti}-\mathrm{V})$ micro alloyed steel under hot compression.

\section{REFERENCES}

Mirzadeh, H. and Najafizadeh, A. (2010). Flow stress prediction at hot working conditions. Mater. Sci. Eng. A, 527, pp. 1160-1164.

Lin, Y.C. and Chen, X.M. (2011). A critical review of experimental results and constitutive descriptions for metals and alloys in hot working, Mater. Des. 32, pp. 1733-1759.

Mirzadeh, H., Cabrera, J.M., Prado, J.M. and Najafizadeh, A. (2012). Modeling and prediction of hot deformation flow curves, Metall. Mater. Trans. A, 43, pp. 108-123.

Rakhshkhorshid, M. and Hashemi, S.H. (2013). Experimental study of hot deformation behavior in API X65 steel, Mater. Sci. Eng. A, 573, pp. 37-44.

Rakhshkhorshid, M. (2015). Modeling the hot deformation flow curves of API X65 pipeline steel, Int. J. Adv. Manuf. Tech., 77, pp. 203-210

Zhu, Y., Zeng, W., Sun, Y., Feng, F. and Zhou, Y. (2011). Artificial neural network approach to predict the flow stress in the isothermal compression of as-cast TC21 titanium alloy. Comp. Mater. Sci., 50, pp. 1785- 1790.

Rakhshkhorshid, M. (2017). A Robust RBF-ANN Model to Predict the Hot Deformation Flow Curves of API X65 Pipeline Steel, IJMF, Iranian Journal of Materials Forming, 4(1), pp. 12-20.

Rath, S., Talukdar, P., Singh, A. P. (2017). Application of Artificial Neural Network for Flow Stress Modelling of Steel. American Journal of Neural Networks and Applications. 3(3), pp. 36-39. 